\title{
Análisis crítico del discurso político en la interpretación simultánea en el Parlamento Europeo
}

Palabras clave: discurso político - interpretación simultánea — análisis crítico del discurso.

\section{Observación participante}

Varios investigadores del análisis del discurso ${ }^{1}$ postulan que, para analizar el discurso, el investigador debe participar en el proceso discursivo y realizar un verdadero trabajo de campo. La observación participante ${ }^{2}$ garantiza conocer el material de primera mano y estar realmente involucrado en el proceso discursivo ${ }^{3}$. Muchos papeles ofrecen la posibilidad de participación en el Parlamento Europeo, pero también conllevan la obligación de preparar, dar o anotar discursos políticos. El trabajo del intérprete simultáneo requiere, por un lado, una preparación perfecta del tema del debate que incluye el conocimiento profundo del funcionamiento del mecanismo europeo, lo que, por otra parte, permite la observación participante. Esta forma de participación en el proceso legislativo permite una inmersión total en el discurso político de las instituciones europeas, sin perder de vista la imparcialidad investigadora a la hora de la selección, categorización y análisis del material lingüístico. Los casi diez años de experiencia en este aspecto se complementan con la investigación doctoral de cuatro años que es punto de partida para la siguiente y más avanzada investigación, que abarca aspectos nuevos, como los aspectos cognitivos a la hora de interpretar simultáneamente un discurso, que queremos plasmar en este artículo.

${ }^{1}$ R. Wodak, M. Meyer (eds.), Métodos de análisis crítico del discurso, Barcelona, Gedisa, 2003 , p. 48.

2 Ibidem, p. 49.

${ }^{3}$ C. López Alonso, Análisis del Discurso, Madrid, Síntesis, 2014, p. 283. 


\section{El contexto}

El intérprete debe disponer del conocimiento temático, cultural y práctico del debate político que compone el contexto discursivo para poder transmitir el mensaje de una intervención política en otro idioma. Por lo tanto, el contexto del discurso interpretado incluye el fondo y las circunstancias del suceso discursivo que facilita su comprensión. Se puede definir como:

algún tipo de entorno, circunstancias para un suceso, acción o discurso. Algo que necesitamos saber para comprender adecuadamente el suceso, la acción o el discurso. Algo que funciona como trasfondo, marco, ambiente, condiciones o consecuencias ${ }^{4}$.

El contexto engloba elementos como los participantes, sus conocimientos previos y la interacción entre ellos, sus roles y objetivos, el marco locativotemporal, el decorado, los actos no verbales, las referencias culturales, científicas, etc. Por consiguiente, el contexto incluye propiedades sociales que facilitan su comprensión e interpretación porque se combinan con elementos cognitivos que incluyen lo que se dice y cómo se dice. Las propiedades sociales del contexto reflejan características sociales como edad, formación, lugar de origen (tipo de vocabulario, sintaxis, gestión de pausas, repeticiones), y se relacionan con las psicológicas (repeticiones, dificultad en expresarse debido al estrés, o seguridad en sí mismo o experiencia como orador reflejada en el discurso, etc.) $)^{5}$. En el discurso político en el Parlamento Europeo el orador puede transmitir conscientemente o no algunos elementos de su formación (recurriendo al lenguaje técnico), origen (empleando regionalismos, o queriendo ocultarlos al hablar bien, gesticulando de forma culturalmente condicionada), edad (usando arcaísmos) ${ }^{6}$. El discurso refleja las características psicológicas del ponente, a lo que contribuyen las realizaciones visuales, o por ejemplo el exceso de gesticulación que denota el nerviosismo o las pausas. De ahí que, en el marco del análisis de discurso y su interpretación, el contexto de un suceso discursivo sea de suma importancia. Las propiedades del contexto afectan tanto a la producción como a la comprensión e interpretación del discurso a otro idioma. Por tanto, el análisis del contexto es esencial para poder interpretarlo porque permite comprender el suceso comunicativo como algo que ocurre en el marco social: "el análisis social del discurso define el texto y el habla como situados: describe el discurso como algo que se realiza en una situación social"7.

El discurso político es un acto social interactivo que nace de un acto discursivo. Esto es, el ponente que toma la palabra (o hace una pausa, o realiza un gesto) expresa el mensaje que tiene intención de comunicar conforme con

\footnotetext{
${ }^{4}$ T. Van Dijk (ed.), El discurso como interacción social, Barcelona, Gedisa, 2000, p. 32.

${ }^{5}$ M. Almeida, Sociolingüística, La Laguna, Universidad de la Laguna, 2003, p. 69.

${ }^{6}$ Ibidem, p. 87.

7 T. Van Dijk (ed.), op. cit., p. 33.
} 
la ideología que representa. Aparte de la ideología directa o indirectamente manifestada a través de su discurso como parte de la información contextual, el ponente interactúa, esto es, hace referencia a lo que dijeron otros participantes del debate, a las propuestas legislativas, a sus autores, a la situación socioeconómica y política relevante, y a la situación discursiva en general. Para realizar una interpretación contextualmente fiel, precisa y natural del discurso a otro idioma, el intérprete debe comprender las características contextuales y de la interacción discursiva.

La identificación de estas características permite al intérprete entender no solo el sentido directo de las palabras del orador, sino también su intención, los significados implícitos, los dobles sentidos y alusiones ${ }^{8}$. En el debate multilingüe en el Parlamento Europeo, donde se entrelazan 23 idiomas, los elementos cognitivos del contexto, los actos mentales, resultan más difíciles de descifrar e interpretar a otro idioma. Se poder identificar, por tanto, las características contextuales y cognitivas, esto es, los modelos mentales, del discurso político para saber interpretarlo. Los modelos mentales están reflejados discursivamente a través de las categorías discursivas. La herramienta idónea para su identificación y comprensión es el conjunto de las categorías discursivas propuestas por Van Dijk en el marco del enfoque del Análisis Crítico del Discurso.

\section{Categorías discursivas}

El enfoque del Análisis Crítico del Discurso de Van Dijk abarca categorías discursivas que describen las características contextuales sociocognitivas del discurso político y reflejan, al mismo tiempo, los modelos mentales del interlocutor. Las categorías propuestas por Van Dijk, Machin y Mayr ${ }^{9}$ adaptadas a lo largo de la investigación a las necesidades del análisis del discurso político multilingüe constituyen la base metodológica. El listado utilizado como herramienta de análisis contiene aproximadamente 20 categorías discursivas. Sin embargo, aquí se describirán solo seis de ellas para demostrar el proceso de su identificación y análisis realizado por el intérprete en su trabajo. La identificación de categorías discursivas facilita al intérprete su posterior transmisión al otro idioma adaptándolas al contexto sociocultural y político. El análisis comparativo de 23 idiomas no habría sido posible en un espacio tan limitado. Por lo tanto, para presentar el proceso de identificación y análisis de las categorías discursivas durante la interpretación simultánea, propone-

${ }^{8}$ T. Van Dijk, "Cognitive context models and discourse", en: M. Stamenow (ed.), Language Structure, Discourse and the Access to Consciousness, Amsterdam, Benjamins, 1997, pp. 189-226.

9 T. Van Dijk, "Política, ideología y discurso", Quorum académico, vol. 2, no 2, julio-diciembre, 2005, pp. 15-47; D. Machin, A. Mayr, How to do Critical Discourse Analysis, London, SAGE, 2014. 
mos la comparación de seis categorías discursivas utilizadas por tan solo dos europarlamentarios, una española y un polaco. Las intervenciones provienen del debate sobre la propuesta de la Comisión Europea sobre la producción de tabaco en la UE. El intercambio de opiniones tuvo lugar en la reunión de la Comisión de Agricultura y Desarrollo Rural en el Parlamento Europeo el 25 de marzo 2013. En el debate hubo solo una intervención en polaco y una en español. Por lo tanto, aunque los discursos varían de longitud, se refieren al mismo tema. Además, las categorías discursivas coinciden en las dos intervenciones, lo que posibilita la comparación de su uso. La identificación y análisis de las categorías discursivas en dos idiomas distintos por parte del intérprete constituye una herramienta cognitiva, que cuando ya está dominada, facilita la interpretación contextual adecuada.

En sus correspondientes intervenciones (véase el Anejo I) María Auxiliadora Correa Zamora, miembro del Partido Popular Europeo y del partido Partido Popular español, y Czesław Siekierski, miembro del Grupo del Partido Popular Europeo y del partido polaco Polskie Stronnictwo Ludowe (Partido Campesino Polaco), coinciden en el uso de las siguientes categorías discursivas mencionadas más abajo. El intérprete después de haberlas detectado realiza, sin cesar de interpretar simultáneamente, el análisis siguiente:

(1) Polarización es una categoría discursiva que corresponde a una oposición de opiniones, posturas, ideologías o personas, instituciones, soluciones etc. expresada a través del discurso. María Auxiliadora Correa Zamora (MACZ) la introduce a través de la categoría discursiva de Orden (véase más abajo), exigiendo datos de la Comisión Europea en las líneas 40 a 43. Esta exigencia es un ataque indirecto y genera polarización entre las dos instituciones:

A este respecto y sin extenderme más, quisiera preguntarle a la Comisión, si tiene previsto a corto, o largo plazo hacer uso de estas prerrogativas y en su caso si aportará elementos científicos sólidos que la avalen.

Czesław Siekierski (CS) recurre a la misma oposición institucional en la línea 9 de su intervención. A través de una Categorización (véase más abajo) clasifica la propuesta de la Comisión como precipitada. Con esta crítica subraya la polarización entre la Comisión y el Parlamento Europeo:

Te propozycje w tej komisji moim zdaniem idą/10 idą/ zbyt daleko (en español ${ }^{11}$ : Estas propuestas de la Comisión van demasiado lejos).

(2) Categorización es una clasificación de la realidad, situación, ideología, solución política, etc. MACZ clasifica positivamente a la Comisión

${ }^{10}$ Signos de transcripción incluyen y corresponden a: / repetición de la misma palabra; // repetición modificada; $((\ldots))$ palabra ininteligible; hhh suspiro.

11 Todas las traducciones son de la autora. 
Europea en la línea 23, porque agradece su esfuerzo en combatir la venta ilícita del tabaco. No obstante, esta introducción positiva sirve para resaltar una crítica posterior:

Hay que aplaudir la buena intención de la Comisión Europea a la hora de proponer un refuerzo de la lucha contra la venta ilícita del tabaco, pero sin embargo considero que existe una contradicción en su planteamiento, pues las prohibiciones que propone, podrían dar precisamente lugar a un aumento del contrabando.

CS categoriza como positivo el enfoque del otro europarlamentario que comparte:

Ja podzielam ten// to// rozsądne podejście pana posła ((Tabaidżi)), który próbuje pogodzić interesy i podejście obu stron, to po pierwsze. (Comparto esta// este// enfoque positivo del europarlementario ((Tabaidżi)) que intenta conciliar los intereses y enfoques de las dos partes, eso primero)

(3) Implicación es una alusión a un significado, a un resultado, o a una solución a través de una referencia al proceso. MACZ, en la línea 18, utiliza una implicación para demostrar el carácter negativo de la disminución de la producción que podría afectar a muchas medianas y pequeñas empresas en la manufactura, transformación, distribución y fabricación de tabaco:

Como consecuencia, muchos puestos de trabajo que generalmente radican en pequeñas y medianas empresas concentradas en el cultivo del tabaco, así como en la manufactura, transformación, distribución y fabricación, serían destruidos.

Otra implicación en su intervención abarca el tema del contrabando, que aumentará en Europa si se eliminan las pequeñas productoras. CS en la línea 5 comparte sus conocimientos en forma de una serie de Implicaciones:

musimy mieć świadomość przemieszczenia produkcji, przemytu, tych różnych negatywnych skutków, które nastąpią, w związku z tym (tenemos que ser conscientes del desplazamiento de la producción, del contrabando, estos diversos efectos negativos que tendrán lugar a raíz de esto).

(4) Especificación consiste en presentar en detalle un hecho, mecanismo, propuesta, ideología, situación, consecuencia, etc. MACZ recurre, en las líneas 11, 12 y 15 a las categorías discursivas de los datos numéricos y del ejemplo para construir una especificación de la situación de la producción de tabaco en la Unión Europea:

Hay que tener en cuenta que// que// la Unión Europea produce el cuatro por ciento del tabaco mundial, e importa más del setenta por ciento del tabaco que consume.

Sigue describiendo problemas económicos que podrían surgir a raíz de la directiva, poniendo de ejemplo la situación en Extremadura: 
Sin embargo, la desaparición de miles de hectáreas que se dedican a este cultivo, pondrían/, podrían crear serios problemas socioeconómicos en regiones como en Extremadura, en España, en las que al menos el veinticinco por ciento de su producción final agraria, procede del cultivo del tabaco.

CS también especifica efectos negativos que se darían si se aplicara la propuesta de la Comisión: desplazamiento de la producción, del contrabando, etc.

(5) Orden es una categoría discursiva que transmite exigencia, presión o urgencia para conseguir algo. MACZ, en la línea 39, pregunta a la Comisión sobre las prerrogativas que le permiten reducir los límites de nicotina y acerca de si tiene pensado facilitar "elementos científicos sólidos" que avalen esta decisión. La ponente no solicita explicación, ni sobre el funcionamiento de las prerrogativas, ni sobre las condiciones de la introducción de los actos delegados, sino que exige datos, recurriendo, con ello, indirectamente a la categoría discursiva de orden:

Por otra parte, entre las prerrogativas de la Comisión se reserva// que se reserva la Comisión, figura la posibilidad en un futuro de reducir los límites de nicotina, lo que podría igualmente tener una incidencia sobre la producción primaria. A este respecto y sin extenderme más, quisiera preguntarle a la Comisión, si tiene previsto a corto, o largo plazo hacer uso de estas prerrogativas y en su caso si aportará elementos científicos sólidos que la avalen.

CS, en cambio, recurre a una orden, un llamamiento a la autoconsciencia, dirigido al grupo al cual pertenece: "musimy mieć świadomość (tenemos que ser conscientes)", en la línea 5.

(6) Emocionalidad es una categoría discursiva que abarca diferentes formas de expresión de sentimientos en el discurso. Por ejemplo, MACZ, en las líneas 36 y 39, critica los actos delegados propuestos por la Comisión. Los describe como preocupantes:

Además, contrariamente a lo que/ a lo que// ha esbozado la/ la/ Comisión en su propuesta, no está claro que beneficie al consumidor europeo, ya que propiciaría un aumento de los productos de contrabando de calidad en muchas ocasiones preocupante, muy preocupante.

CS critica el enfoque de la Comisión en las líneas 6 y 7 de su intervención. Para reforzar su crítica expresa el miedo de las posibles consecuencias negativas, tales como el traslado de la producción y contrabando: "porque yo tengo miedo de que". Además, la solución que propone es un llamamiento a la sensatez que Siekierski realza emocionalmente con ironía:

No, więcej rozsądku w tym podejściu, bo ja się boję, że za chwilę usłyszę o//, a może jest taka analiza, o wpływie palenia tytoniu na emisję $\mathrm{CO}_{2}$ (Bueno, más sensatez en este enfoque porfavor, porque me temo que pronto me dirán//, o que existe un estudio ya sobre la influencia del tabaquismo en la emisión del $\mathrm{CO} 2$ ). 


\section{Conclusiones}

El intérprete analizando el discurso llega a la siguiente conclusión: la forma de recurrir a las siguientes categorías discursivas polarización, categorización, implicación, especificación, orden, emocionalidad varía entre las intervenciones polaca y española. La polarización introducida por la ponente española es más proactiva que la constatación del ponente polaco. Correa Zamora se basa en la orden (una exigencia) y Siekierski en una categorización. Sin embargo, los dos ponen de relieve la oposición entre el Parlamento y la Comisión. Las categorizaciones de los dos ponentes constituyen un binomio: positivo y negativo. Correa Zamora clasifica de forma positiva para preparar un ataque, lo que convierte su mensaje en negativo, y Siekierski constata directamente la clasificación positiva.

Los dos ponentes recurren a las implicaciones para, a través de la presentación de las consecuencias negativas, demostrar la inadecuación de la propuesta. El uso de implicaciones es casi idéntico en el caso de ambos ponentes, así que no debería provocar problemas a la hora de su identificación e interpretación. El mecanismo también resulta parecido en el caso de especificación. Los ponentes recurren a las categorías datos (Correa Zamora) o ejemplos (ambos) para describir la situación y los efectos negativos si la propuesta legislativa desemboca en un acto vigente. Las especificaciones están muy claras para un intérprete porque no exigen ninguna operación cognitiva para comprenderlas. Están servidas directamente en bandeja a través de enumeraciones concretas.

La orden está introducida por la ponente española de forma directa, a través de una exigencia. Correa Zamora pide "datos sólidos". Sin embargo, Siekierski utiliza la orden de forma indirecta, dirigida a "nosotros mismos". Subraya la necesidad de darse cuenta de los posibles resultados negativos de la propuesta de la Comisión. Su enfoque es más colectivista que el de Correa Zamora, que resulta más individualista. Ambos ponentes recurren a la emocionalidad para subrayar su opinión: la inadecuación de la propuesta de la Comisión. Correa Zamora lo hace en un tono alarmista, en cambio, Siekierski recurre a la ironía. En ambos casos la emocionalidad es fácilmente identificable.

Resumiendo, el uso de las categorías discursivas podría variar dependiendo del carácter de la persona, experiencia del orador, cualidades de negociador, etc. Pero vemos claramente, al realizar el breve análisis al cual da tiempo ejecutando la interpretación simultánea que el uso de las categorías discursivas varía también en función del idioma, aquí, en español y en polaco. El uso de las categorías discursivas es fácilmente identificable y su análisis indica al intérprete cómo expresar el mismo significado en otro idioma, traduciendo ideas y no palabras, adaptando el mensaje al contexto sociocultural y político y reduciendo la distancia contextual de la realidad del idioma materno del ponente y del intérprete. Este análisis es solo un breve ejemplo del Análisis Crítico del Discurso aplicado a las intervenciones interpretadas simultáneamente en el contexto multilingüe del Parlamento Europeo. Sin embargo, 
demuestra la utilidad del enfoque crítico que permite facilitar al trabajo del intérprete.

\title{
Anejo
}

\author{
Intervenciones de la reunión de la Comisión de Agricultura y del Desarrollo \\ Rural del día 25 de marzo de 2013.
}

\section{Intervención de María Auxiliadora Correa Zamora en transcripción de la autora ${ }^{12}$ :}

Gracias señor presidente. Buenas tardes.

Me gustaría hacer algunas observaciones a esta, a esta propuesta de directiva.

Efectivamente como se ha dicho aquí, aquí esta tarde, como se ha puesto de manifiesto, esta directiva no afecta directamente al cultivo del tabaco, pero los efectos indirectos podrían, podrían conllevar sin duda, pues nuevos ajustes drásticos en el tejido productor de países como Italia, Polonia, Bulgaria, Grecia o España entre otros... Pues afectan directamente a los productores los cuales, como ya se ha dicho también aquí esta tarde, se concentran en estructuras familiares y en explotaciones poco, poco mecanizadas. La Comisión debería tener, tener en cuenta, que la eventual desaparición de la producción tabaquera europea como resultado de las medidas emprendidas por la Unión Europea, (\#) no serían una garantía para reducir el consumo. Hay que tener en cuenta que/ que/ la Unión Europea produce el cuatro por ciento del tabaco mundial, e importa más del setenta por ciento del tabaco que consume. Sin embargo, la desaparición de miles de hectáreas que se dedican a este cultivo, pondrían, podrían crear serios problemas socioeconómicos en regiones como en Extremadura, en España, en las que al menos el veinticinco por ciento de su producción final agraria, procede del cultivo del tabaco. Como consecuencia muchos puestos de trabajo que generalmente radican en pequeñas y medianas empresas concentradas en el cultivo del tabaco, así como en la manufactura, transformación, distribución y fabricación serían destruidos. Además, contrariamente a lo que// a lo que// ha esbozado la/ la/ Comisión en su propuesta, no está claro que beneficie al consumidor europeo, ya que propiciaría un aumento de los productos de contrabando de calidad en muchas ocasiones preocupante, muy preocupante. Hay que aplaudir la buena intención de la Comisión Europea a la hora de proponer un refuerzo de la lucha contra la venta ilícita del tabaco, pero sin embargo considero que existe una contradicción en su planteamiento, pues las prohibiciones que propone, podrían dar precisamente lugar a un aumento del contrabando. En países como Polonia, en donde el treinta por ciento del consumo corresponde a cigarrillos mentolados y Bulgaria con un cuarenta por ciento de consumidores de cigarrillos finos, la prohibición de estas categorías podría disparar en ambos países, países, el comercio ilegal para satisfacer la demanda tradicional. Me gustaría también subrayar aquí esta tarde, la necesidad de disociar claramente en este debate la problemática del consumo, que sin duda nadie niega que es nocivo para la salud y el apoyo al cultivo. Desde esta Comisión de Agricultura considero que debemos trabajar, para defender los intereses de nuestros agricultores y salvaguardar que toda iniciativa legislativa que les afecte, esté basada en evidencias científicas sólidas y que cumplan el principio jurídico de proporcionalidad. Para terminar quisiera llamar la atención sobre el hecho de que si bien esta directiva, como decía al principio de mi intervención, no afecta directamente al cultivo, es preocupante, como decía el señor ponente, que la Comisión se otorgue en su proyecto la posibilidad de incorporar actos delegados, hhh, novedades en varios ámbitos de la directiva, incluidos los ingredientes y aditivos autorizados. Lo que no deja de plantear pues cierta, cierta incertidumbre. Por otra parte, entre las prerrogativas

${ }^{12}$ Comisión de Agricultura y Desarrollo Rural <http://downloads.europarltv.europa.eu/ $>25$ de marzo 2013. 
de la Comisión se reserva, que se reserva la Comisión, figura la posibilidad en un futuro de reducir, los límites de nicotina lo que podría igualmente tener una incidencia sobre la producción primaria. A este respecto y sin extenderme más, quisiera preguntarle a la Comisión, si tiene previsto a corto, o largo plazo hacer uso de estas prerrogativas y en su caso si aportará elementos científicos sólidos que la avalen. Muchas gracias.

\section{Intervención de Czesław Siekierski en transcripción de la autora:}

Ja bardzo krótko, bo nie mamy czasu. Ja podzielam ten// to// rozsądne podejście pana posła ((Tabaidżi)), który próbuje pogodzić interesy i podejście obu stron, to po pierwsze; po drugie musimy mieć świadomość przemieszczenia produkcji, przemytu, tych różnych negatywnych skutków, które nastąpią, w związku z tym. Hhh... No, więcej rozsądku w tym podejściu, bo ja się boję, że za chwilę usłyszę o, a może jest taka analiza, o wpływie palenia tytoniu na emisję $\mathrm{CO}_{2}$. I dlatego bym, no, szukał tutaj racjonalnego rozwiązania, jakiegoś etapowego. Te propozycje w tej komisji moim zdaniem idą/ idą/ zbyt daleko. Dziękuję.

\section{Referencias bibliográficas}

ALMEIDA M.

2003 Sociolingüistica, La Laguna, Universidad de la Laguna. LÓPEZ ALONSO C.

2014 Análisis del Discurso, Madrid, Síntesis.

MACHIN D., MAYR A.

2013 How to do Critical Discourse Analysis, London, SAGE.

WODAK R., MEYER M. (eds.)

2003 Métodos de análisis crítico del discurso, Barcelona, Gedisa.

VAN DIJK T.A.

1997 "Cognitive context models and discourse”, en: Stamenow M. (ed.), Language Structure, Discourse and the Access to Consciousness, Amsterdam, Benjamins, pp. 189-226.

1997 "Discurso, cognición y sociedad", Signos 8(22), pp. 66-74.

2000 (ed.) El discurso como como interacción social, Barcelona, Gedisa.

2005 "Política, ideología y discurso", Quorum académico, vol. 2, n 2, julio-diciembre, pp. $15-47$.

\section{Páginas web}

Comisión de Agricultura y Desarrollo Rural, <http://downloads.europarltv.europa.eu/> 25 de marzo 2013. 


\section{Interpreter as participant. Critical Political Discourse Analysis in multilingual simultaneous interpretation}

Keywords: Political discourse - simultaneous interpretation - critical discourse analysis.

\section{Abstract}

This paper examines a participative approach of a simultaneous interpreter in the Critical Analysis of Political Discourse. It describes two examples of Polish and Spanish MEPs' interventions about tobacco production in the EU in a debate that took place during a meeting of the Committee of Agriculture and Rural Development in the European Parliament. The analysis of the discourse indicates the mechanism of identification of discursive categories possible in both languages, which can be crucial for an interpreter in transmitting the contextualised message into another language. These categories can be a tool to improve interpreting of different contextual characteristics in the multicultural and multilingual political debate. 